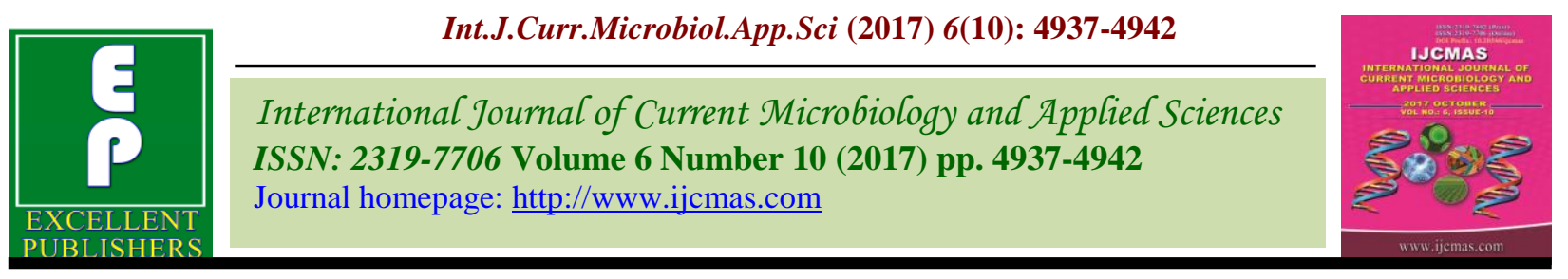

Original Research Article

https://doi.org/10.20546/ijcmas.2017.610.466

\title{
A Protocol for Callus Induction in Chilli Genotypes from Hypocotyls as Explant
}

\author{
Sanjeev Kumar ${ }^{1}$, Naresh Mehta ${ }^{2}$, Jaywant Kumar Singh², \\ Manoj Kumar ${ }^{2 *}$ and Anil Kumar ${ }^{2}$ \\ ${ }^{1}$ Indian Institute of Soybean research, Indore, India \\ ${ }^{2}$ Department of Plant Pathology, College of Agriculture, CCS HAU, Hisar 125 004, India \\ *Corresponding author
}

\begin{tabular}{l} 
K e y w or d s \\
$\begin{array}{l}\text { Callus, Chilli, Growth } \\
\text { regulators, Tissue } \\
\text { culture, Hypocotyls. }\end{array}$ \\
\hline Article Info \\
$\begin{array}{l}\text { Accepted: } \\
29 \text { September } 2017 \\
\text { Available Online: } \\
\text { 10 October } 2017\end{array}$ \\
\hline
\end{tabular}

The yield potential as well as quality of chilli is affected by a number of biotic and abiotic stresses. The genetic improvement of this crop, especially for characters like resistance to biotic and abiotic stresses using conventional breeding methods are laborious, time taking and also needs a large experimental area. So, an attempt was made to study callus induction in chilli genotypes by using hypocotyls as explant to complement conventional breeding and expedite capsicum improvement. The study was carried out on callogenic response of chilli species with different hormones revealed that MS medium supplemented with NAA $2.5 \mathrm{mg} / 1+$ BAP $2.5 \mathrm{mg} / 1$ was found most suitable for callus induction to both the genotypes viz., Capsicum annuum and Capsicum frutescens. When NAA and BAP were used in combination early initiation of the callus was observed with fragile and pale yellow colour in both the genotypes of chilli. Among the chilli genotypes evaluated, the average callus formation was $(77.24 \%)$ in case of $C$. annuиm, whereas $(79.20 \%)$ in $C$. frutescens. Hence, callus induction was significantly better in $C$. frutescens as compared to C. anпиит.

\section{Introduction}

Chilli (Capsicum annuum L.) commonly known as pepper is one of the most important spice crop grown in the world. There are about 25-30 species of Capsicum out of which five species are most common and currently cultivated Csilléry, (2006). C . annuum is the most widespread and widely cultivated species in subtropics and temperate countries Belletti et al., (1998). It is a native of tropical America and widely grown in India, China, Peru, Bangladesh, Pakistan and other European countries. India is the largest producer, consumer and exporter of chilli in the world. In India highest area under chilli
(26\%) is in Andhra Pradesh as well as maximum production $(53 \%)$ comes from this state only. The yield potential, quality as well as nutritional value of chilli is affected by a number of biotic and abiotic stresses. However, genetic improvement of this crop, especially for characters like resistance to biotic and abiotic stresses using conventional breeding methods are laborious, time taking and also needs a large experimental area. So, different biotechnology techniques like plant tissue culture and recombinant DNA technologies are powerful tools that can complement conventional breeding and 
expedite Capsicum improvement. Thus, application of tissue culture and genetic transformation has led to significant development in chilli pepper plants.

Callus induction in any crop is pre-requisite for its utilization in tissue culture based techniques like somaclonal variation, screening of calli against biotic and abiotic stresses, regeneration of plants and transgenic plant development. Gunay and Rao (1978) for the first time tested different hormonal regimes for tissue culture in Capsicum using MS medium (Murashige and Skoog, 1962).

Callus induction depends on composition of nutritive media, growth regulators and other organic additives. The objective of this study is to develop a protocol for efficient callus induction in chilli genotypes derived from hypocotyl segments using MS medium and its combinations with different growth regulators.

\section{Materials and Methods}

\section{Raising of seedlings}

The seeds of two chilli genotypes comprising Capsicum annuum var. Pusa Jwala and Capsicum frutescens var. California wonder were taken for the study. The seeds of two genotypes of chilli were taken in a beaker and soaked for 2-3 minutes in tap water containing four drops of teepol. These were washed 4 times with tap water and then surface sterilized by immersing in 0.1 per cent (w/v) $\mathrm{HgCl}_{2}$ for 8 minutes, which were subsequently rinsed thoroughly 4 times with double distilled sterilized water to eliminate the traces of $\mathrm{HgCl}_{2}$ in aseptic conditions. The surface sterilized seeds were then inoculated on MS medium without hormone and incubated in BOD incubator at $25 \pm 1{ }^{\circ} \mathrm{C}$ in white fluorescent light (1500 lux) for 16 hour and in dark for 8 hour (Fig. 1).

\section{Preparation of media for tissue culture studies}

Different media used in the present study were prepared by modifying the MS medium (Murashige and Skoog, 1962). Different nutrient stocks containing major nutrients, minor nutrients, chelating agent, vitamins and growth regulators were prepared according to the standard procedures. Storage of stock solutions of major elements, minor elements and growth regulators were done in a refrigerator at $4^{\circ} \mathrm{C}$. Chemicals like glycine, nicotinic acid, major elements, minor elements etc. were also stored in refrigerator. For preparing one litre of MS basal medium following nutrient stocks were mixed in about $500 \mathrm{ml}$ of double distilled water in sequence.

Final volume of the media used in the studies was made to one litre after adding appropriate stock solutions and growth regulators. Agaragar was added after standardizing the $\mathrm{pH}$ (5.8) of the solution and dissolved by heating in a microwave oven before being poured in Erlenmeyer flasks used for autoclaving.

\section{Inoculation and incubation of hypocotyls segments}

Hypocotyl segments measuring 5-6 mm were excised from 7 days old seedlings and implanted on MS medium supplemented with different concentrations of growth regulators i.e. auxins and cytokinins alone or in combination. Each treatment contained 6 replications and the experiment was designed in CRD (completely randomized design). The inoculated flasks and Petri plates were incubated at $25 \pm 1{ }^{\circ} \mathrm{C}$ for one month under 16 hour fluorescent light (1500 lux) and 8 hour dark and observations on percent callus induction and morphological characters were recorded after one month. Different media used for callus induction studies were as follows (Table 1). 


\section{Results and Discussion}

Callus induction from hypocotyl segments was evident through general surface swelling of the explants after 3-4 days of inoculation and with the appearance of dividing cells at both ends of hypocotyls segments, which was followed by division over entire surface that further lead to the development of callus (Fig. 2). Among different media used for callus induction, calli was established on MS media supplemented with different conc. of IBA, 2, 4-D, IAA, NAA, BAP, NAA + BAP. The results revealed that medium supplemented with BAP (1 mg/l) and NAA+BAP (2.5 mg/l) gave cent per cent callus induction (Table 2). Further increase in the concentration of BAP reduced the callus induction. The nature of the calli i.e colour and structure depended on using different types and combinations of growth regulators. Application of IAA and IBA as growth regulator induced small, brown callus with roots, whereas the callus formed in this medium having 2,4-D was friable and creamy white in colour. Similarly, application of NAA as growth regulator

Fig.1 Shooting and rooting on MS basal media from hypocotyls

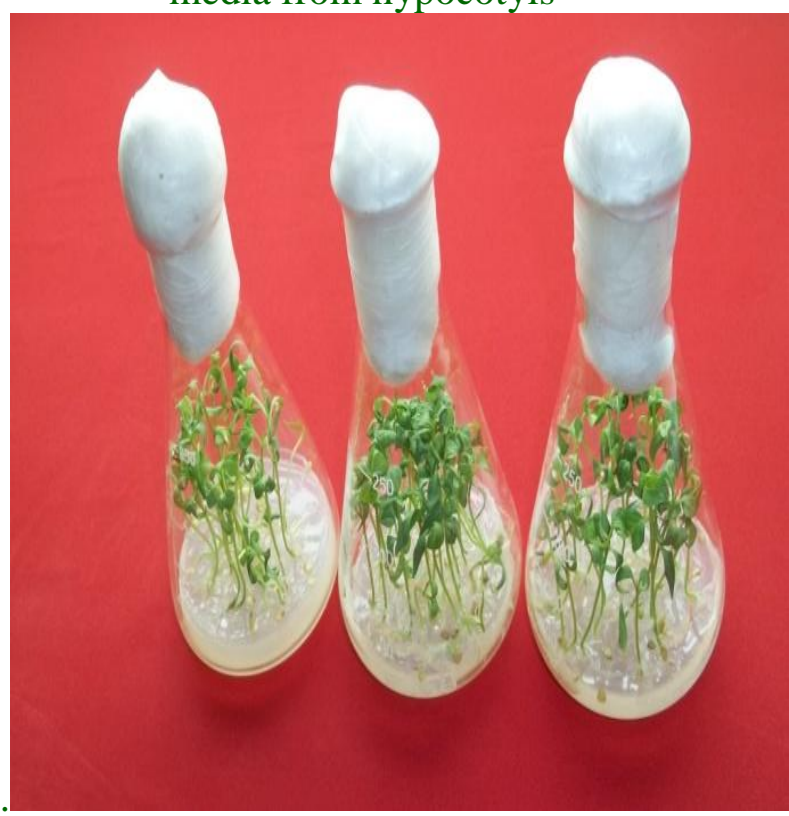

produced pale yellow and fragile calli and in case of BAP application compact green, cottony callus was formed. But when NAA and BAP were used in combination early initiation of the callus was observed with fragile and pale yellow colour in both the genotypes of chilli (Fig. 3). MS basal medium without any growth regulator did not induce any calli formation.

From these observations it is apparent that callus induction increased with addition of auxin or cytokinin or combination of both in MS basal media. Thus callus induction was better with auxin addition. Maximum callus induction was recorded with MS basal media with $2.5 \mathrm{mg} / \mathrm{l}$ auxin or cytokinin. So, NAA + BAP $2.5 \mathrm{mg} / \mathrm{l}$ gave 100 per cent callus formation and this medium was selected for further experiment. Among the chilli genotypes evaluated, the average callus formation was $(77.24 \%)$ in case of $C$. annuum, whereas $(79.20 \%)$ in $C$. frutescens. Hence, callus induction was significantly better in $C$. frutescens as compared to $C$. annuum.

Fig.2 Dividing cells at hypocotyls ends

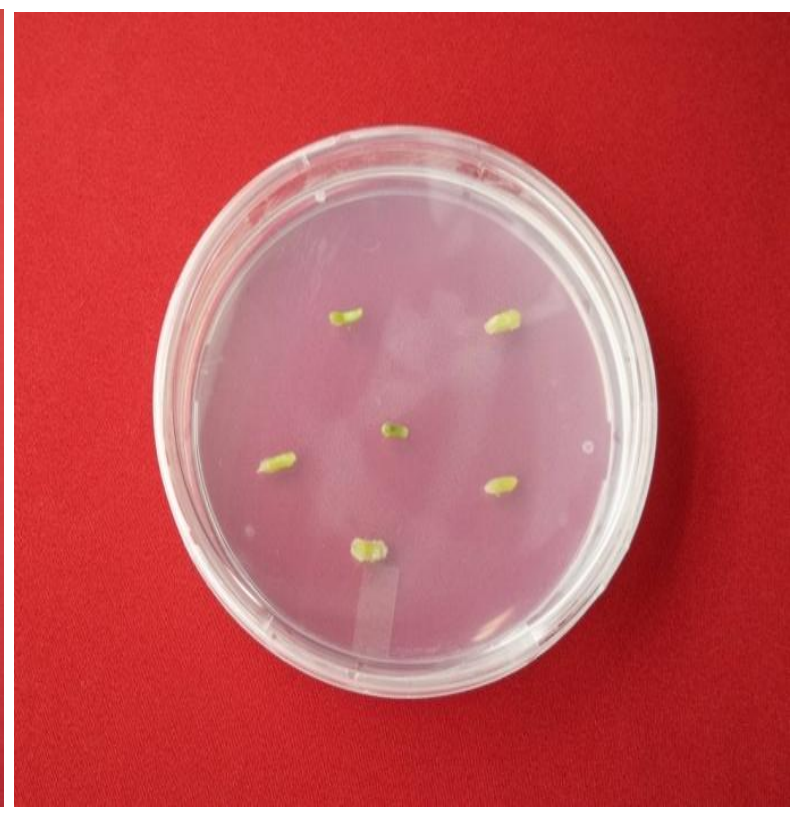


Fig.3 Callogenic ability of Capsicum annuum in response to different growth hormones

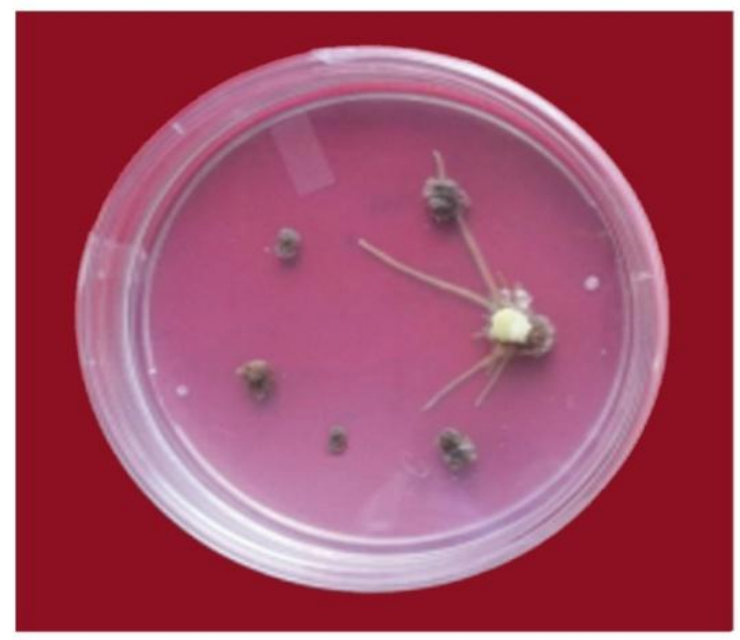

IBA- 2.5\%

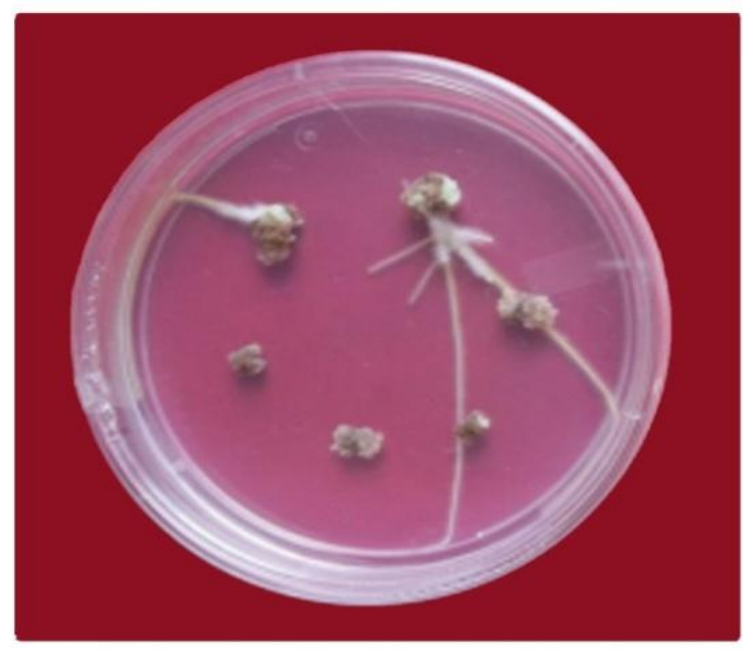

IAA- 2.5\%

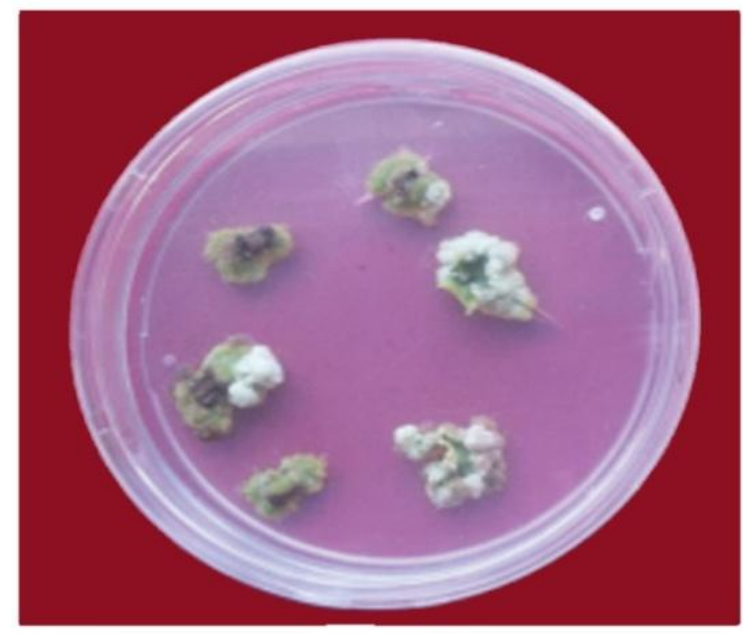

BAP- 1.0\%

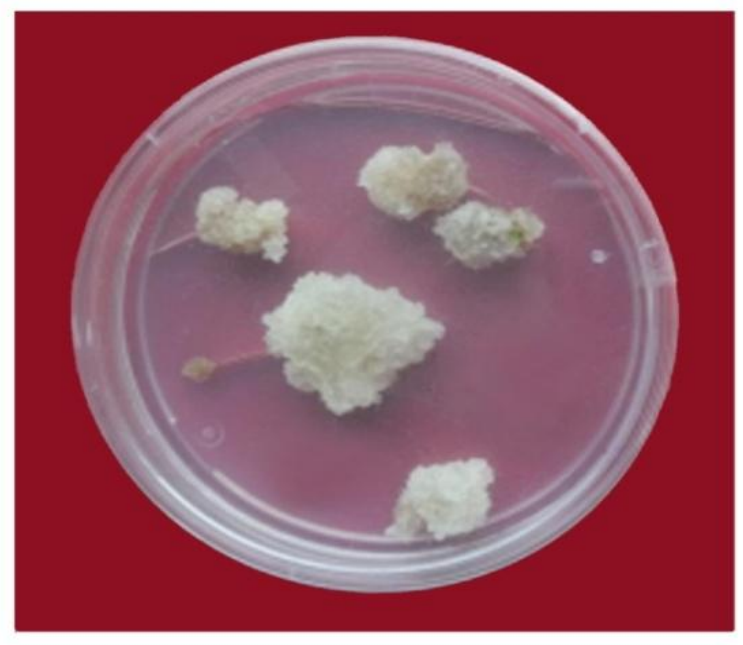

2,4-D -2.5\%

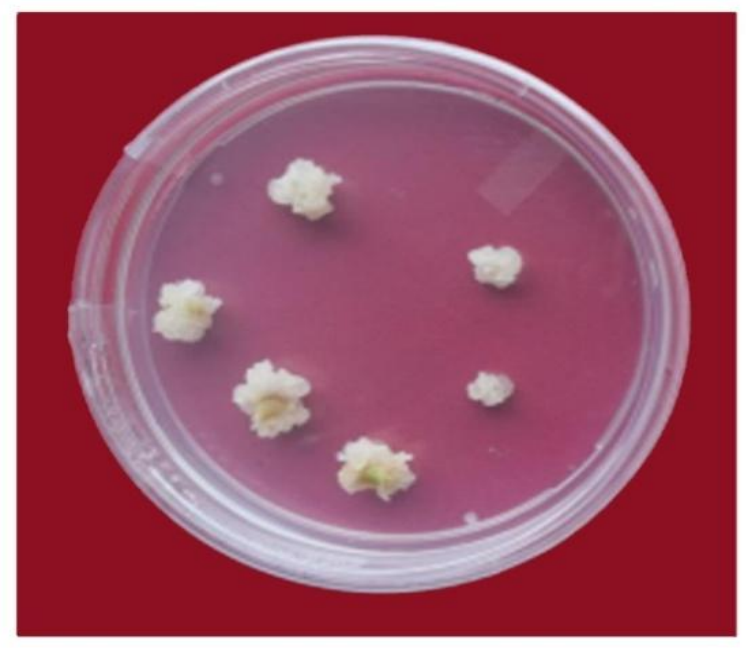

NAA $-2.5 \%$

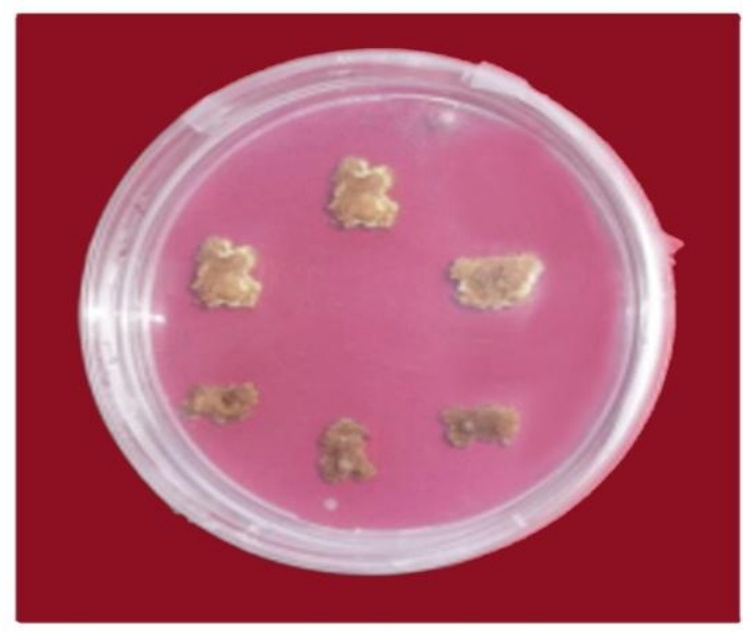

NAA +BAP-2.5\% 
Table.1 List of media used for callus induction

\begin{tabular}{|l|c|}
\hline I. Auxin & Medium code \\
\hline MS basal & $\mathrm{A}_{1}$ \\
\hline MS basal +IBA $(0.5 \mathrm{mg} / 1)$ & $\mathrm{A}_{2}$ \\
\hline MS basal +IBA $(1 \mathrm{mg} / 1)$ & $\mathrm{A}_{3}$ \\
\hline MS basal +IBA $(2.5 \mathrm{mg} / 1)$ & $\mathrm{A}_{4}$ \\
\hline MS basal +IBA $(5 \mathrm{mg} / 1)$ & $\mathrm{A}_{5}$ \\
\hline MS basal +2,4-D $(0.5 \mathrm{mg} / 1)$ & $\mathrm{A}_{6}$ \\
\hline MS basal +2,4-D $(1 \mathrm{mg} / 1)$ & $\mathrm{A}_{7}$ \\
\hline MS basal +2,4-D $(2.5 \mathrm{mg} / 1)$ & $\mathrm{A}_{8}$ \\
\hline MS basal +2,4-D $(5 \mathrm{mg} / 1)$ & $\mathrm{A}_{9}$ \\
\hline MS basal +IAA $(0.5 \mathrm{mg} / 1)$ & $\mathrm{A}_{10}$ \\
\hline MS basal +IAA $(1 \mathrm{mg} / 1)$ & $\mathrm{A}_{11}$ \\
\hline MS basal +IAA $(2.5 \mathrm{mg} / 1)$ & $\mathrm{A}_{12}$ \\
\hline MS basal +IAA $(5 \mathrm{mg} / 1)$ & $\mathrm{A}_{13}$ \\
\hline MS basal +NAA $(0.5 \mathrm{mg} / 1)$ & $\mathrm{A}_{14}$ \\
\hline MS basal +NAA $(1 \mathrm{mg} / 1)$ & $\mathrm{A} 15$ \\
\hline MS basal +NAA $(2.5 \mathrm{mg} / 1)$ & $\mathrm{A} 16$ \\
\hline MS basal +NAA $(5 \mathrm{mg} / 1)$ & $\mathrm{A} 17$ \\
\hline II. Cytokinin & \\
\hline MS basal +BAP $(0.5 \mathrm{mg} / 1)$ & $\mathrm{C} 1$ \\
\hline MS basal +BAP $(1 \mathrm{mg} / 1)$ & $\mathrm{C} 2$ \\
\hline MS basal +BAP $(2.5 \mathrm{mg} / 1)$ & $\mathrm{C} 3$ \\
\hline MS basal +BAP $(5 \mathrm{mg} / 1)$ & $\mathrm{C} 4$ \\
\hline III. Auxin + Cytokinin & \\
\hline MS basal +NAA $(0.5 \mathrm{mg} / 1)+\mathrm{BAP}(0.5 \mathrm{mg} / 1)$ & $\mathrm{AC} 1$ \\
\hline MS basal +NAA $(1 \mathrm{mg} / 1)+\mathrm{BAP}(1 \mathrm{mg} / 1)$ & $\mathrm{AC} 2$ \\
\hline MS basal +NAA $(2.5 \mathrm{mg} / 1)+\mathrm{BAP}(2.5 \mathrm{mg} / 1)$ & $\mathrm{AC} 3$ \\
\hline MS basal +NAA $(5 \mathrm{mg} / 1)+\mathrm{BAP}(5 \mathrm{mg} / 1)$ & $\mathrm{AC} 4$ \\
\hline
\end{tabular}

Table.2 Effect of various growth media on callus induction (\%) in different chilli genotypes

\begin{tabular}{|c|c|c|c|}
\hline Auxin & Capsicum Annuum & Capsicum frutescens & Callus growth \\
\hline MS basal (control) & 0.00 & 0.00 & No callus \\
\hline MS basal +IBA $(0.5 \mathrm{mg} / 1)$ & 64.00 & 69.19 & Brown, small callus with roots \\
\hline MS basal + IBA $(1 \mathrm{mg} / 1)$ & 87.50 & 90.90 & Brown, small callus with roots \\
\hline MS basal +IBA (2.5 mg/1) & 91.66 & 95.23 & Brown, small callus with roots \\
\hline MS basal +IBA $(5 \mathrm{mg} / 1)$ & 70.83 & 74.50 & Brown, small callus with roots \\
\hline MS basal +2,4-D $(0.5 \mathrm{mg} / 1)$ & 66.66 & 70.37 & Friable, creamy white callus \\
\hline MS basal +2,4-D (1 mg/1) & 80.76 & 80.64 & Friable, creamy white callus \\
\hline MS basal +2,4-D $(2.5 \mathrm{mg} / 1)$ & 91.66 & 87.09 & Friable, creamy white callus \\
\hline MS basal +2,4-D (5 mg/1) & 72.00 & 74.50 & Friable, creamy white callus \\
\hline MS basal +IAA $(0.5 \mathrm{mg} / 1)$ & 62.18 & 68.72 & Brown, small callus, with roots \\
\hline MS basal +IAA (1 mg/1) & 73.91 & 76.19 & Brown, small callus, with roots \\
\hline MS basal +IAA $(2.5 \mathrm{mg} / 1)$ & 78.26 & 85.00 & Brown, small callus,with roots \\
\hline MS basal +IAA $(5 \mathrm{mg} / 1)$ & 65.30 & 74.50 & Brown, small callus, with roots \\
\hline MS basal +NAA $(0.5 \mathrm{mg} / 1)$ & 63.63 & 64.70 & Pale yellow, fragile calli \\
\hline MS basal +NAA $(1 \mathrm{mg} / 1)$ & 75.00 & 80.36 & Pale yellow, fragile calli \\
\hline MS basal +NAA $(2.5 \mathrm{mg} / 1)$ & 91.66 & 88.82 & Pale yellow, fragile calli \\
\hline MS basal +NAA (5 mg/1) & 66.66 & 73.33 & Pale yellow, fragile calli \\
\hline \multicolumn{4}{|l|}{ II. Cytokinin } \\
\hline MS basal +BAP $(0.5 \mathrm{mg} / 1)$ & 80.76 & 85.36 & Compact green, cottony callus \\
\hline MS basal +BAP $(1 \mathrm{mg} / 1)$ & 100.00 & 100.00 & Compact green, cottony callus \\
\hline MS basal +BAP $(2.5 \mathrm{mg} / 1)$ & 92.85 & 90.00 & Compact green, cottony callus \\
\hline MS basal +BAP $(5 \mathrm{mg} / 1)$ & 76.00 & 72.38 & Compact green, cottony callus \\
\hline \multicolumn{4}{|l|}{$\begin{array}{c}\text { III. Auxin + Cytokinin } \\
\end{array}$} \\
\hline MS basal +NAA $(0.5 \mathrm{mg} / 1)+\mathrm{BAP}(0.5 \mathrm{mg} / 1)$ & 88.00 & 87.54 & Pale yellow, fragile calli with early initiation \\
\hline MS basal +NAA $(1 \mathrm{mg} / 1)+\mathrm{BAP}(1 \mathrm{mg} / 1)$ & 95.83 & 97.28 & Pale yellow, fragile calli with early initiation \\
\hline MS basal +NAA $(2.5 \mathrm{mg} / 1)+\mathrm{BAP}(2.5 \mathrm{mg} / 1)$ & 100.00 & 100.00 & Pale yellow, fragile calli with early initiation \\
\hline MS basal +NAA (5 mg/1) +BAP (5 mg/1) & 96.15 & 93.48 & Pale yellow, fragile calli with early initiation \\
\hline
\end{tabular}

C.D $(\mathrm{P}=0.05)$ Species $(\mathrm{C})-0.64$ Hormone $(\mathrm{H})-2.28$ Interaction $(\mathrm{C} \mathrm{X} \mathrm{H})-3.23$ 
In the present investigation, chilli hypocotyl segments of 5-8 $\mathrm{mm}$ from seven days old seedlings were used for callus culture. Hypocotyl segments of both genotypes $C$. annuum and $C$. frutescens were placed on different medium supplemented with varying levels of growth hormones for callus initiation.

It was observed that MS medium supplemented with NAA+BAP $(2.5 \mathrm{mg} / \mathrm{l})$ showed 100 per cent callus induction and the callus formed showed an early initiation. Kumar et al., (2010) observed MS medium supplemented with BAP (2.0 mg/l) and 2, 4-D $(1.0 \mathrm{mg} / \mathrm{l})$ was found to be the best medium for maximum callus induction from hypocotyl explants of Pusa Jwala.

Similarly, Ray et al., (2010) reported highest amount of callus induction on MS medium containing $2.0 \mathrm{mg} / \mathrm{l} \mathrm{BAP}$ and $0.5 \mathrm{mg} / \mathrm{l} \mathrm{NAA}$ in egg-plant.

This might be due to the availability of auxin in optimum concentration for activation of expansin enzyme resulting in loosening of explant cell wall leading to increase in initial growth of explant.

Optimum concentration of auxin also caused acidification of explant cell wall by activation of expansin enzyme which brought about the initial growth of the callus. Early callus initiation might be due to early biochemical conversion of NAA to functional form (Hasnat et al., 2007).

\section{Acknowledgement}

The author gratefully acknowledges the Department of Biotechnology and Molecular Biology, CCS HAU, Hisar and for providing facilities to carry out research programme.

\section{References}

Belletti, P., Marzachi, C., and Lanteri S.1998. Flow cytometric measurement of nuclear DNA content in Capsicum. Plant Syst Evol 209: 85-91.

Csilléry, G., 2006. Pepper taxonomy and the botanical description of the species. Acta Agron Hung 54: 151-66.

Gunay A L and Rao P S.1978. In vitro plant regeneration from hypocotyl and cotyledon explants of red pepper (Capsicum). Plant Sci Lett 11: 365-372.

Hasnat, R., Abbasi N A, Ahmad, T., and Hafiz, F A.2007. Induction and regeneration of hypocotyls derived calli in hot chilli varieties. Pak. J. Bot. 39 (5): 1787-1795.

Kumar A O, Subba T S and Rupavati, T.2010. In vitro induction of callusogenesis in chilli peppers. In. J Curr Res 3: 42-45.

Murashige T and Skoog F.1962. A revised medium for rapid growth and bioassay with tobacco tissue culture. Physiol Plant 15: 473-497.

Ray B P, Hassan L and Sarker S K.2010. Plant regeneration from seedling derived explants through callus of eggplant (Solanum melongena L.). The Agriculturists 8: 98-107.

\section{How to cite this article:}

Sanjeev Kumar, Naresh Mehta, Jaywant Kumar Singh, Manoj Kumar and Anil Kumar. 2017. A Protocol for Callus Induction in Chilli Genotypes from Hypocotyls as Explant. Int.J.Curr.Microbiol.App.Sci. 6(10): 4937-4942. doi: https://doi.org/10.20546/ijcmas.2017.610.466 